\title{
Rootstock on vine performance and wine quality of 'Syrah' under double pruning
}

\section{management}

Frederico Alcântara Novelli Dias ${ }^{1 *}$, Renata Vieira da Mota ${ }^{1}$, Claudia Rita de Souza ${ }^{1}$, Rodrigo Meirelles de Azevedo Pimentel ${ }^{1}$, Laís Cristina de Souza², André Luiz de Souza², Murillo de Albuquerque Regina ${ }^{1}$

${ }^{1}$ Agronomical Research Institute of Minas Gerais Technological Center of Grape and Wine Research, Av. Santa Cruz, 500, C.P. 33 - 37780-000 - Caldas, MG - Brazil. ${ }^{2}$ Federal University of Alfenas - Chemical Dept., Rod. José Aurélio Vilela, 11999 - 37715-400 - Poços de Caldas, MG - Brazil.

${ }^{*}$ Correspondent author <frederico_novelli190@hotmail.com> Edited by: Axel Garcia y Garcia

Received October 13, 2015

Accepted April 21, 2016
ABSTRACT: In the Brazilian Southeast, the production of high quality wines is attained by a new management approach called double pruning. This management changes the harvesting of wine grape (Vitis vinifera L.) from wet summer to dry winter through a two pruning procedures carried out during the year. The first pruning is done during the winter to induce a vegetative cycle (all clusters are removed) and a second pruning is done during the summer to induce the reproductive cycle. In this study, ten different rootstocks were compared in order to optimize yield and wine quality of Syrah vines conducted under autumn-winter season by double pruning approach. Syrah grapevines grafted onto 'Rupestris du Lot' and 'AC 766' showed the highest pruning weight, while '110 Richter' and '161-49 Courdec' induced the lowest cane vigor. The average production of two seasons identified 'IAC 766', 'Kober 5BB' and 'Rupestris du Lot' as the most productive rootstocks. In both seasons, the grape quality was more influenced by the plant development status than by rootstocks. 'Syrah' wine from vigorous and high yielding rootstocks, 'IAC 766' and 'Rupestris du Lot', showed satisfactory wine phenolic composition and alcohol/ acidity balance. This study showed that vigorous rootstock increased yield without compromising grape and winter wine quality of Syrah grapevines subjected to double pruning management in the Brazilian Southeast.

Keywords: Vitis vinifera, autumn-winter season, vigor, yield, berry quality

\section{Introduction}

In the Brazilian Southeast, the double pruning, a new management approach for vineyards, has opened a new possibility for fine wine production during the autumn-winter season (Regina et al., 2011). This procedure transfers the grape ripening period from high temperatures during the day and night and high rainfall of summer to low rainfall and high thermal amplitude of autumn-winter season (Favero et al., 2011). The climate during autumn-winter is favorable to sugar accumulation and synthesis of phenolic compounds in berries when compared to traditional management (Mota et al., 2010; Favero et al., 2011). Although this new management approach seems very promising, other cultural practices, such as grafting combinations, need to be evaluated to optimize grape yield and wine quality.

Grafting is a compulsory practice because Vitis vinifera is highly susceptible to Phylloxera infestation. Nowadays, the grafting technique has also been used to control vigor, yield, wine quality and to increase tolerance to environmental stress (Jackson and Lombard, 1993). The rootstock replaces all the root system of the scion, altering water and mineral absorption, affecting the physiological process and consequently vine vigor and yield (Soar et al., 2006; Souza et al., 2015). Furthermore, the classification of rootstocks as high, moderate or low vigor inductors can change according to scion interaction and edaphoclimatic conditions (Kidman et al., 2013; Renouf et al., 2010). The knowledge about rootstock-scion interaction provides the basis for selecting a range of possible combinations suitable for the management of a particular vineyard.

To date, only two studies on rootstock recommendation for double pruning management have been published. The first study showed that 'Syrah' grafted onto traditional '1103 Paulsen' had a better vegetative and reproductive balance as compared to 'SO4' and '110 Richter' (Dias et al., 2012). In the second, Souza et al. (2015) showed that the best performance for 'Cabernet Sauvignon' was obtained with more vigorous rootstocks such as 'Kober 5BB', 'IAC 766', '1045 Paulsen' and 'SO4'. Although rootstocks recommendations for double pruning management are available there is no information about the effect of rootstock-scion interaction on winter wine quality. Hence, the proposal of this study was to evaluate the influence of ten rootstocks on vegetative vigor, yield, grape and wine composition of 'Syrah' conducted under double pruning management.

\section{Materials and Methods}

\section{Plant material and experimental design}

The experimental site was located on commercial vineyard in Andradas $\left(22^{\circ} 04^{\prime} \mathrm{S}, 46^{\circ} 34^{\prime} \mathrm{W}\right.$, altitude of $920 \mathrm{~m}$ ), south of Minas Gerais state, Brazil. The experimental site was installed in 2008 using 'Syrah', clone 174 ENTAV-INRA, grafted onto ten rootstocks commonly used in tropical and subtropical climates: '1103 Paulsen' (1103P) (rootstock most used for Vitis vinifera production in Brazil), '1045 Paulsen' (1045P), '99 Richter' (R99), '110 Richter' (R110) (Vitis berlandieri $\times$ Vitis rupestris); 
'101-14 Millardet et de Grasset' (101-14MGT) (Vitis riparia $\times$ Vitis rupestris); 'SO4', 'Kober 5BB' (Kober) (Vitis berlandieri $\times$ Vitis riparia); '161-49 Couderc' (161-49C) (Vitis riparia $\times$ Vitis berlandieri); Rupestris du Lot (Rup) (Vitis rupestris); IAC 766 ((Vitis riparia $\times$ Vitis cordifolia) $\times$ Vitis caribea). The experiment was carried out during 2011 and 2012 seasons when plants were three and four years old.

The double pruning management was applied according to the methodology described by Favero et al. (2011). The first pruning was done in Aug. (vegetative cycle) for latent bud formation and the second pruning was done in Jan. (reproductive cycle) for grape production. During the vegetative cycle, all clusters were removed at green pea stage of berries. The purpose was not to harvest in the summer season, but to have the inflorescence primordia differentiated into latent buds. The second pruning (yield pruning) is done in lignified shoots to induce the reproductive cycle. In both cycles, the buds were sprayed after pruning with hydrogen cyanamide at $5 \%$ to stimulate and standardize the budburst. Plants were trained in vertical shoot position with bilateral cordons and pruned in two-node spurs, for both pruning, totaling 20 latent buds per plant on average. Vines and rows were spaced $1.40 \mathrm{~m}$ and $2.70 \mathrm{~m}$, respectively, totaling 2,645 plants $\mathrm{ha}^{-1}$. The vineyard was not irrigated. The experimental design was completely randomized with three replicates for each rootstock, represented by five plants per plot, totaling an experimental area of 150 plants.

\section{Agronomical and physicochemical analyses}

Dry weight of pruned shoot and leaf area were evaluated as a measure of vine vigor. The pruned shoots were collected from each plant and dried in forced air oven at $60{ }^{\circ} \mathrm{C}$ until constant dry weight was reached. This parameter was measured annually at winter season after grape harvest. The leaf area was estimated according to Regina et al. (2000) using one plant per plot at the beginning of veraison, after shoot trimming.

Three 'Syrah' vines were hand-harvested from each plot on 20 July 2011 and 13 July 2012. The average bunch weight were assessed from 30 bunches randomly collected from each treatment replicate. The $\mathrm{pH}$, total titratable acidity (TTA) and total soluble solids (TSS) were evaluated by 100 random berries collected for each replicate. The average vine production was estimated by multiplying the number of bunches per plant by the average bunch weight of the plot. Yield was obtained by multiplying the average vine production by the number of plants $\mathrm{ha}^{-1}$. The ratio between leaf area and fruit weight (expressed as $\mathrm{m}^{2} \mathrm{~kg}^{-1}$ ) and the ratio between vine production and pruning weight (expressed as $\mathrm{kg} \mathrm{kg}^{-1}$ ) were calculated to evaluate the balance between vegetative and reproductive development on autumn-winter cycle.

The phenolic quality of berries was also analyzed at harvest. Three randomized samples of 100 berries were collected for each treatment. A sample of $150 \mathrm{mg}$ of skin was crushed on liquid nitrogen and homogenized in automatic with extracting acidified methanol solution $(1 \% \mathrm{HCl})$. The concentration of anthocyanins in berry skin was determined by the $\mathrm{pH}$ differential method (Giusti and Wrolstad, 2000). Total phenolics were determined by Folin-Ciocalteau method based on a standard gallic acid curve (Amerine and Ough, 1980).

Winemaking and physicochemical quality of wine In the 2012 season, harvested grapes were delivered at winery and stored at $4{ }^{\circ} \mathrm{C}$ for $24 \mathrm{~h}$. For each treatment, $10 \mathrm{~kg}$ of grape clusters were destemmed and crushed. The must with average TSS of $20.7^{\circ} \mathrm{Brix}, \mathrm{pH}$ 3.56 , TTA of $6.98 \mathrm{~g} \mathrm{~L}^{-1}$ and density of 1.093 for all treatments was placed in $13.25 \mathrm{~L}$ glass carboy. The musts were inoculated with rehydrated wine yeast Saccharomyces cerevisiae $\times S$. kudriavzevii and added with $80 \mathrm{mg}$ $\mathrm{SO}_{2} \mathrm{~kg}^{-1}$.

Wine density was determined daily during alcoholic fermentation at $21^{\circ} \mathrm{C}$. When the density reached 990 $\mathrm{mg} \mathrm{L}^{-1}$, wines were transferred to $13.25 \mathrm{~L}$ glass carboys for malolactic fermentation that was carried out at $21^{\circ} \mathrm{C}$, without inoculation, until malic acid was not detected by the paper chromatography method (Amerine and Ough, 1980). The wines were racked to remove lees, treated with potassium metabisulfite $\left(35 \mathrm{mg} \mathrm{SO}_{2} \mathrm{~L}^{-1}\right)$ and were kept at $3{ }^{\circ} \mathrm{C}$ for $15 \mathrm{~d}$ to allow tartaric stabilization. The wines were allowed to age in $375 \mathrm{~mL}$ glass bottles at 15 ${ }^{\circ} \mathrm{C}$ in a dark cell for 16 months. The 'Kober' treatment was lost because its glass carboy was accidentally broken.

The physicochemical analyses consisted of alcohol, TTA ( $\mathrm{g} \mathrm{L}^{-1}$ tartaric acid), volatile acidity ratified for free $\mathrm{SO}_{2}$ (Vac; $\mathrm{g} \mathrm{L}^{-1}$ acetic acid), $\mathrm{pH}$, and ashes alkalinity (meq L-1) (Amerine and Ough, 1980). Color intensity, color hue, polymerized pigments and total polyphenol indices (TPI 280nm) were evaluated by spectrophotometry (Ribéreau-Gayon et al., 2006a). Total flavanoid content was evaluated by Bate-Smith reaction (Ribéreau-Gayon et al., 2006a). Anthocyanins and phenolics were measured by the $\mathrm{pH}$ differential method and Folin-Ciocalteau method, respectively (Amerine and Ough, 1980; Giusti and Wrolstad, 2000).

The statistical analyses were performed using the SISVAR (Computer Statistical Analysis System, version 4.6). A one-way ANOVA was carried out for wine. For field evaluation and physicochemical composition of grape, a two-way ANOVA was used with rootstock and season as the main factors. The mean values were compared using a Scott Knott test, at $5 \%$ probability. This test was chosen to identify groups of rootstocks that induce similar performance on Syrah grapevine. For wine data, the principal component analysis (PCA) was also carried out by R Program (R Project for Statistical Computing, version 3.1.3) in order to ascertain that trends or group formations of wine samples were from different from rootstocks. 


\section{Results}

\section{Vegetative and reproductive growth}

The vegetative vigor evaluated by leaf area and pruning weight of 'Syrah' was affected by rootstock but mainly by season. All treatments showed higher vegetative vigor in the 2012 season, when the plants reached four years of age. Leaf area showed an increase of $66 \%$ on average for all treatments, while pruning weight rose over $76 \%$.

There was no difference in leaf area induced by rootstocks in the 2011 season with an average of $2.26 \mathrm{~m}^{2}$ per plant. In the 2012 season, however, 'R110', 'SO4' and '161-49' showed a mean leaf area of $3.01 \mathrm{~m}^{2}$ per plant, lower than the average $4.07 \mathrm{~m}^{2}$ per plant of the other treatments. These rootstocks also did not show significant increase on mean leaf area between seasons.

Pruning weight increased from an average of 105.6 g per plant for all treatments in 2011 to $186.01 \mathrm{~g}$ per plant in the 2012 season. In both seasons, 'Syrah' grafted onto 'IAC 766' and 'Rup' showed the highest pruning weight, on average 159.2 and $295.3 \mathrm{~g}$ per plant in the 2011 and 2012 seasons, respectively. The lowest cane vigor induced was observed for rootstocks '161-49C', 'R110' and 'R99', on average 70.1 and 143.2 g per plant, respectively.

There was a sharp increase in vine production between seasons from $1.30 \mathrm{~kg}$ in 2011 to $2.81 \mathrm{~kg}$ in 2012 , mainly due to an increase in the number of clusters, on average, 12.5 and 23.1 in the 2011 and 2012 seasons, respectively. In general, the most vigorous rootstocks also generated the highest production and yield parameters. Grapevines grafted onto 'IAC 766', 'Rup' and 'Kober' showed an average for vine production of 1.82 and 3.95 $\mathrm{kg}$, 16 and 28 clusters per plant and cluster weight of 115.4 and $138.5 \mathrm{~g}$ in the 2011 and 2012 seasons, respectively. Mean yield parameters for low cane yield were observed for rootstocks 'R110', 'R99' and '161-49C' with 0.79 and $1.75 \mathrm{~kg}, 9$ and 17 clusters per plant and cluster weight of 89.6 and 95.0 g, respectively, in the 2011 and 2012 seasons. 'IAC 766', 'Rup' and 'Kober' interactions enabled to reach yield up to $10 \mathrm{t} \mathrm{ha}^{-1}$ in 4 years-old Syrah vines.

Pruning weight was positively correlated with vine production, indicating that yield was increased by the largest vines (Figure 1). However, there was an increase in vine production until the mean values of pruning weight reached around $200 \mathrm{~g}$ per plant. After this limit, there was no yield increment as observed for rootstocks 'IAC 766' and 'Rup' as compared to 'Kober'. The rootstock '161-49C' induced the lowest means values of pruning weight and consequently the lowest means values of yield (less than $1 \mathrm{~kg}$ per vine) in both seasons. Therefore, in both seasons, '161-49C' also induced the highest leaf area: fruit weight ratio (expressed as $\mathrm{m}^{2} \mathrm{~kg}^{-1}$ ) (Figure 2). The most significant differences among rootstocks for crop load were observed in 2012 where 'IAC 766', 'Rup', '1045 P', 'SO4' and 'Kober' promoted the lowest values whereas the intermediate values were promoted by '1103P', 'R110', 'R99' and '101-14'.

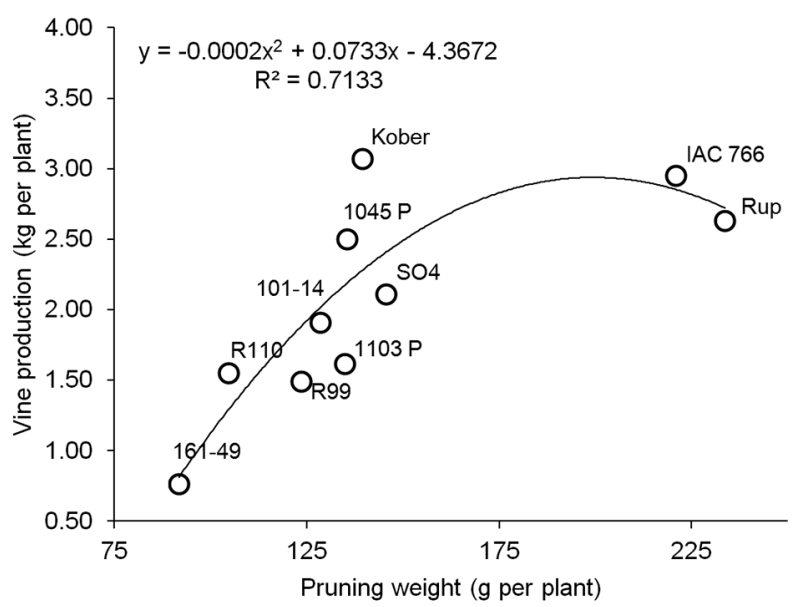

Figure 1 - Ratio between vine production and pruning weight of 'Syrah' grafted onto ten different rootstocks. Each point was calculated by average of mean values of vine production and pruning weight from the 2011 and 2012 seasons.

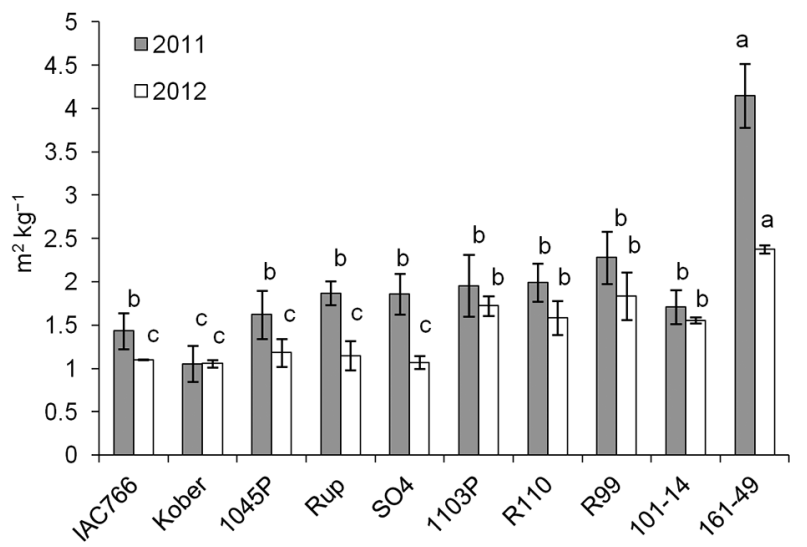

Figure 2 - Ratio between leaf area and fruit weight $\left(\mathrm{m}^{2} \mathrm{~kg}^{-1}\right)$ of 'Syrah' onto 10 rootstocks in 2011 and 2012. Means followed by the same letters, in each season, was not significantly different $(p<0.05)$ by Scott Knott test. Values are means \pm Standard Error.

\section{Grape composition}

There was no influence of rootstock on berry composition. 'Kober' showed a slight tendency to reduce $\mathrm{pH}$ in the must, with mean $\mathrm{pH}$ values of $3.39 \mathrm{com}$ pared to an average of 3.49 of other rootstocks in both seasons.

The average must composition was 21.9 and $20.5^{\circ}$ Brix, pH 3.43 and 3.52 and total acidity of 8.32 and $7.66 \mathrm{~g} \mathrm{~L}^{-1}$ in the 2011 and 2012 seasons, respectively.

Total phenolic compounds and anthocyanins in berry skin were also not affected by rootstocks when compared in the same season. The mean anthocyanin content of all treatments was 123.3 and $125.9 \mathrm{mg} 100$ $\mathrm{g}^{-1}$ of berry in the 2011 and 2012 seasons, respectively, while total phenolics were on average 328.2 and 311.1 mg $100 \mathrm{~g}^{-1}$ of berry, respectively. 
Vines grafted onto 'IAC 766' and '161-49' showed reduction on anthocyanin content between seasons, from 130 to 118 and from 126.0 to $103.0 \mathrm{mg} 100 \mathrm{~g}^{-1}$ of berry, respectively, while in 'SO4' there was a slight

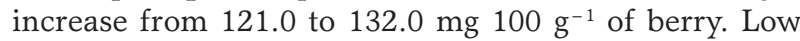
cane yield rootstocks 'R110', 'R99' and '161-49' showed reduction in total phenolic of berry skin between seasons, from 366.0 to 294.0 , from 334.0 to 309.0 and from 333.0 to 263.0 , respectively.

\section{Winter wine composition}

Aged Syrah wines from different rootstocks under double pruning management had a mean alcohol content of $12^{\circ} \mathrm{GL}$, total acidity $5.7 \mathrm{~g} \mathrm{~L}^{-1}$ of tartaric acid, $\mathrm{pH} 3.91$, $0.66 \mathrm{~g} \mathrm{~L}^{-1}$ of acetic acid and ashes alkalinity of 21.68 meq $\mathrm{L}^{-1}$. Although there were no differences the phenolic composition in berry skin between treatments, wine phenolics and color traits showed fluctuation between rootstocks. After 16 months of aging in bottles, the mean anthocyanin content was $140.15 \mathrm{mg} \mathrm{L}^{-1}$, with the highest content observed in 'R99' (169.21 $\left.\mathrm{mg} \mathrm{L}^{-1}\right)$ and the lowest in '161-49' (99.04 $\mathrm{mg} \mathrm{L}^{-1}$ ). 'R99' also pointed out in phenolics (1.49 $\mathrm{g} \mathrm{L}^{-1}$ ), flavonoids (1.60 $\left.\mathrm{g} \mathrm{L}^{-1}\right)$ and TPI (40.17). Mean values for these parameters were $1.29 \mathrm{~g}$ $\mathrm{L}^{-1}, 1.34 \mathrm{~g} \mathrm{~L}^{-1}$ and 35.51, respectively.

All treatments showed high-polymerized pigment index (PPI), over $70 \%$. Although 'R99' showed the highest anthocyanin content, its PPI was the lowest, $70 \%$, which may have contributed to the low value of color intensity (9.53). Conversely, '161-49' obtained the highest values of PPI (82\%) and color intensity (12.45). There were no differences in the participation of OD 420 (37 $\%)$ or OD $520(48 \%)$ to color intensity between treatments but the contribution of OD 620 (15\%) was observed in '161-49' with a percentage of $17 \%$.

The characterization of 'Syrah' wines from different rootstocks after 16 months of aging in bottles was based on the multivariate statistical analysis. The principal component analysis was applied in order to ascertain that trends or group formations of wine samples occurred according to physicochemical properties such as TTA, Vac, pH, ashes alkalinity and alcoholic strength (Figure 3), and to phenolic composition and color traits (Figure 4).

Concerning the physicochemical properties, component 1 explained $41 \%$ and component $2,26 \%$ of variation between 'Syrah' wines (Figure 3). The least vigorous and productive rootstocks '161-49' and 'R110' were loaded positively in the right quadrant while all other treatments were loaded negatively in the left quadrant with most of the physicochemical properties. There was a trend to high alcoholic strength in wines from 'Syrah' grapevine grafted onto 'Rup' and 'R 99' followed by 'IAC 766 '. Wines from 'Syrah' grafted onto '1045 P' showed a trend to higher TTA content as compared to other treatments, followed by 'IAC 766', 'Rup' and 'R99'. On the other hand, '1103 $\mathrm{P}^{\prime}$ and '1045 $\mathrm{P}^{\prime}$ induced the highest volatile acidity in wines. Moreover, the $\mathrm{pH}$ of 'Syrah'

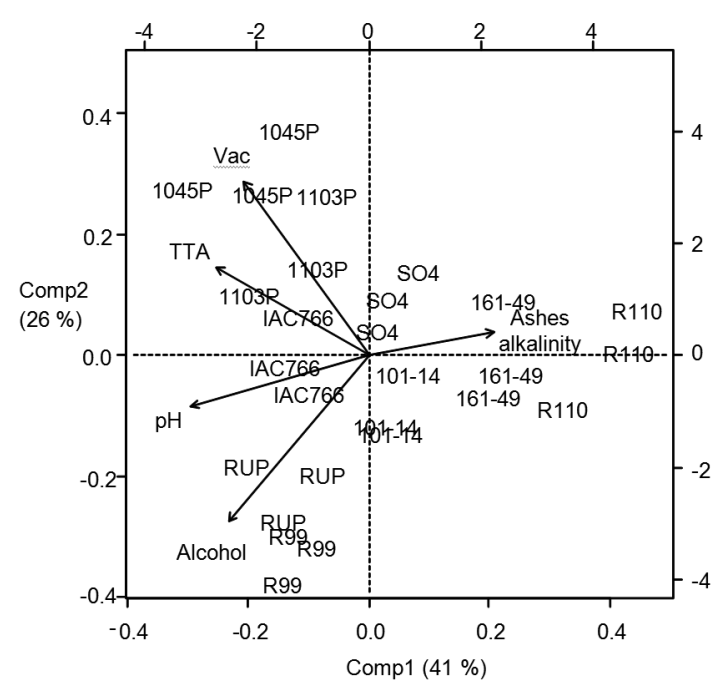

Figure 3 - Principal components analysis of physicochemical properties of winter wines from 'Syrah' grafted onto different rootstocks in 2012. The wines aged 16 months in bottle. Each data represents one laboratorial replicate. (Vac: Volatile acidity; TTA: Total titratable acidity)

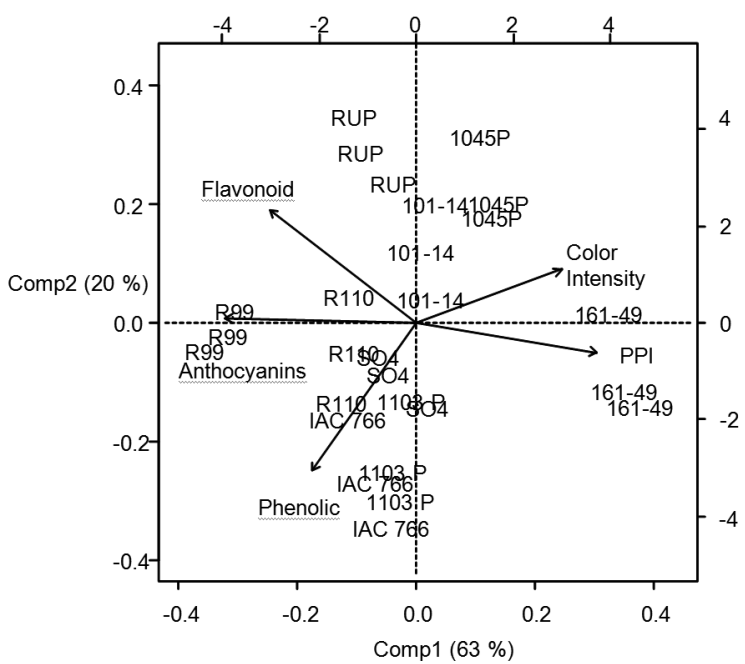

Figure 4 - Principal components analysis of phenolic composition and color traits of winter wines from 'Syrah' grafted onto different rootstock in 2012. The wines aged 16 months in bottle. Each data represents one laboratorial replicate. (PPI: Polymerized pigments indices).

wine from '1045 P' 'SO4', '161-49C' and 'R 110' tended to be lower between treatments. Ash alkalinity showed little relation with rootstock treatments.

The principle component analysis of the phenolic composition and color traits variables explained $83 \%$ of variation between different wines and the first component was responsible for over $60 \%$ (Figure 4). Color intensity was negatively loaded with anthocyanins but was highly correlated with polymerized pigments index 
(PPI). Four distinct groups of rootstocks were separated in the PCA plot: 'R99' stood out with high anthocyanin, total phenolics and flavonoid concentration, however, with low PPI and color intensity. '161-49C' showed an opposite trend with high color intensity and PPI. All other treatments were drawn together in the middle of the graph. 'Rup', 'R110' and '101-14' had a trend to higher anthocyanins and flavonoid concentration than 'IAC766', '1103P' and 'SO4', which showed more total phenolic content. On the other hand, '1045P' showed a tendency to higher color intensity and PPI. In general, these rootstocks induced intermediate characteristics of phenolic composition and color traits to 'Syrah' wines.

The relation of 'Syrah' wine quality and vine balance conferred by different rootstocks was also assessed. The Principal Component Analysis was applied in order to ascertain that trends or group formations of wine samples occurred according to vigor (pruning weight), vine production, phenolic composition and color traits (Figure 5). Component 1 and component 2 were responsible for over $80 \%$ of variations. Pruning weight and vine production did not show negative relationship with phenolic composition and color intensity of 'Syrah' wines. 'IAC 766' and 'Rup' grouped as the most vigorous and productive rootstocks without impairment on anthocyanins or flavonoid content. '161-49', 'R99' and ' $110 \mathrm{R}$ ' were the least vigorous and productive rootstocks but with differences in color intensity and anthocyanins. The other treatments were drawn together in the middle as intermediate productive treatments ('1045P', '1103P', 'SO4' and '101-14') with similar phenolic composition and color.

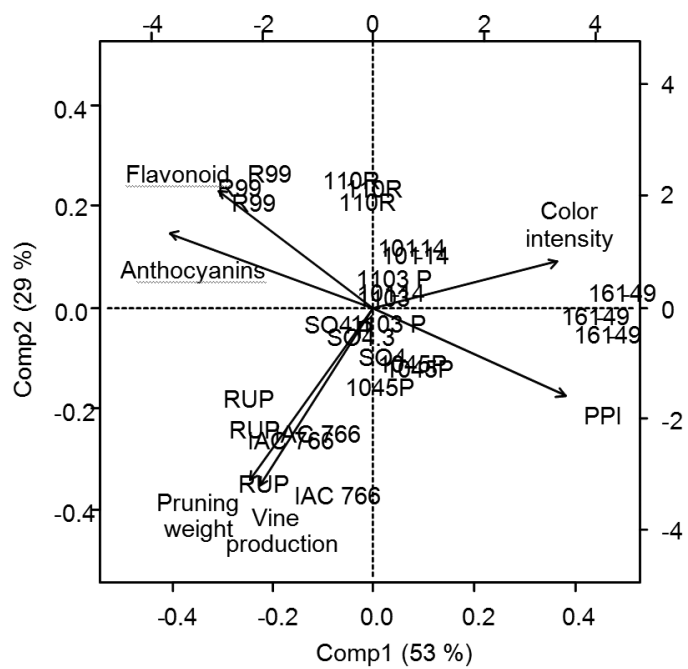

Figure 5 - Principal components analysis for phenolic composition and color traits of winter wine, and pruning weight and vine production of Syrah grafted onto different rootstock in 2012. The wines aged 16 months in bottle. Each data for wine qualities represents one laboratorial replicate and each data for vine traits represent field replicate. (PPI: Polymerized pigments indices).

\section{Discussion}

Rootstock effects on vegetative and reproductive vigor The present study showed that some rootstocks were more suitable to improve vigor and yield of 'Syrah' grown during autumn-winter through double pruning management. In both growing seasons, the highest vegetative vigor was induced by 'Rup' and 'IAC766' whereas the grapevines grafted onto '161-49C', 'R110' and 'R99' had the lowest vegetative development as shown mainly by pruning weight. Pruning weight measurements were more efficient to detect differences between rootstocks than leaf area because it is a seasonally integrated measurement of vine vigor, and the pruning is carried on shoots developed during all growing season (Smart and Robinson, 1991). Under traditional vineyard management, 'Rup' is classified as a high vigor rootstock according to the literature (Satisha et al., 2010). In Brazilian viticulture, 'IAC 766' is a high vigorous rootstock developed for table grapes production. However, Souza et al. (2015) showed that this Brazilian rootstock could be also used to improve the yield of poor fruitset cultivar such as Cabernet Sauvignon under double pruning management in cool climate.

In this study, the smaller size of 'Syrah' vine grafted onto less vigorous rootstock such as '161-49' was probably due to thin roots, superficial root system and lower power of soil penetration, typical characteristics of hybrids of Vitis riparia $\times$ Vitis berlandieri (Walker and Clingeleffer, 2009). On the other hand, Bassoi et al. (2007) showed that the larger root system of 'IAC 572 ', a hybrid also originated from Vitis caribea, such as 'IAC 766', contributed to the highest vegetative vigor and yield of 'Syrah'. The size, density and efficiency of the root system are involved in the regulation of shoot growth and biomass accumulation. The subterranean growth of grapevines is in balance with its aerial vegetative growth (Smart et al., 2006).

It is well known that under traditional vineyard management, low-moderate vigor rootstocks are more recommended for production of high quality wine grape than vigorous rootstock. Several studies have shown the negative effects of high vigor on yield and wine grape quality due to impairment on bud fertility (Vasconcelos et al., 2009), light in the fruit zone (Pereira et al., 2006) and on vegetative and reproductive balance (Soar et al., 2006). However, our results showed that high cane vigor up to mean values of pruning weight of $200 \mathrm{~g}$ per plant did not affect negatively the yield of Syrah under double pruning management since there was a positive correlation between vegetative vigor and grape production (Figure 1), as also shown by Main et al. (2002). Although there was a trend to reduce yield after this limit, grapevines grafted onto 'IAC 766' and 'Rup' still showed crop level mean values higher than $2.5 \mathrm{~kg}$ per vine as well as 'Kober'. On the other hand, '161-49' showed crop level mean values lower than $1.0 \mathrm{~kg}$ per vine, linked to the lowest vegetative development of shoots between all treatments. 
Syrah vineyards grafted onto less vigorous rootstocks such as '1103P', 'SO4' and 'R110' under double pruning management took seven years of vineyard installation to reach the yield of $10 \mathrm{t} \mathrm{ha}^{-1}$ (Dias et al., 2012) while in this work, this yield was obtained in four years with old Syrah vines grafted onto 'IAC 766', 'Kober' and 'Rup'. Furthermore, Souza et al. (2015) showed that rootstocks 'IAC 766' and 'Kober' also improved production of 'Cabernet Sauvignon' under double pruning management in a high altitude region of southern Minas Gerais State.

All rootstocks induced a higher yield in the 2012 season. The lowest yield in 2011 was probably due to the age of vineyard with consequently lower shoot number per vine and clusters per plant.

According to the leaf area fruit-weight ratio, which is used as an indicator of vine balance, the leaf area required to ripen the grape of several $V$. vinifera varieties ranges between 0.8 and $1.4 \mathrm{~m}^{2} \mathrm{~kg}^{-1}$ of fruit (Kliewer and Dokoozlian, 2005). In 2012, the grapevine grafted onto the most vigorous rootstocks also showed a better balance as compared mainly to grapevines drafted onto moderate vigor rootstocks such as ' $1103 \mathrm{P}^{\prime}$ frequently used in Brazilian viticulture for the production of fine wine (Figure 2). These results suggest that the Syrah leaf area induced by the most vigorous rootstocks was enough to ripen their heavy crop.

\section{Rootstock effects on grape composition}

Rootstocks did not influence berry composition in the harvest. In the 2011 season, 'R110' and '161-49' induced lower total acidity in must. The low vigor of these plants, as shown by pruning weight below $70 \mathrm{~g}$ per plant, may have contributed to a greater exposure of clusters to sun light and consequently higher acidity degradation (Spayd et al., 2002). However, in the 2012 season, when pruning weight was over $120 \mathrm{~g}$ per plant for all rootstocks, there were no differences between treatments. 'Kober' contributed to lower $\mathrm{pH}$ in both seasons. The $\mathrm{pH}$ and potassium are important factors that affect the quality of grape juice as well as the microbiological and physicochemical stability of the wine (Kodur et al., 2013). Unfortunately, this treatment was lost during winemaking and we could not check this trend in the wine composition.

Lower TSS and higher pH were observed in 2012. This characteristic can be explained by the larger number of clusters per plant that influenced the source-sink balance. Moreover, the increased vegetative growth of 4-year-old plants could have allowed a higher rootstock system development and consequently higher nutrient uptake, which probably contributed to increase the $\mathrm{pH}$.

Vigorous and productive rootstocks normally delay vegetative growth and berry sugar accumulation (Main et al., 2002). Nevertheless, in this study, all rootstocks induced similar range of berry sugar concentration. The means values of TSS for each season $21.9^{\circ}$ Brix and $20.5^{\circ}$ Brix, respectively, were similar to common values found in other regions of Minas Gerais State (Dias et al., 2012). These values are still similar to 'Syrah' vines grown in warm climate, e.g. Spain (Ortega-Regules et al., 2008).

Phenolic composition of berries was also poorly affected by rootstocks. The increased vegetative and reproductive vigor of Syrah grafted onto most vigorous rootstock did not affect negatively the phenolic maturation, suggesting that the vines were well balanced as mentioned above. On the other hand, a reduction in total phenolics of berry skin between seasons was only induced by less vigorous rootstocks '161-49C', 'R110' and 'R99'. These rootstocks showed almost a two-fold increase in pruning weight from 2011 to 2012. The high increase in plant vigor may have decreased the skin proanthocyanidin mean degree of polymerization in shaded fruits (Cortell et al., 2005). However, it is important to highlight that the values of anthocyanin and total phenolic for all seasons and rootstocks remained within the expected range for quality wine, i.e. $30-750 \mathrm{mg}$ of anthocyanin and 260-900 mg of phenolic per $100 \mathrm{~g}$ of berries (Mazza and Miniati, 1993).

\section{Rootstock effects on wine composition}

Red wine quality is influenced by grape quality factors such as TSS, TTA, $\mathrm{pH}$, total phenolics and anthocyanins. The balance between alcohol and total acidity is important for wine sensorial quality especially for crisp and fresh taste (Rühl, 2000). Rootstocks usually alter these factors indirectly, by balance of vigor and production (Jackson and Lombard, 1993). The productive and vigorous rootstocks 'IAC766' and 'Rup' induced Syrah wines with high alcoholic strength and TTA as well as less vigorous 'R99' rootstock. Nevertheless two of the less vigorous and productive rootstocks 'R110' and '161$49^{\prime}$ were grouped together with the lowest acidity, $\mathrm{pH}$ and alcoholic strength (Figure 3). These results show a weak correlation between vine vigor and production with alcoholic and acidity composition of winter wines.

The phenolic maturation of grapes is strongly linked to wine quality. The phenolic composition of aged Syrah winter wines from 'IAC 766' and 'Rup' also did not show great differences as compared to wines from less vigorous rootstocks 'SO4', '1103P', '101-14' and '1045P'. However, treatments with pruning weight below 160 g per plant presented higher color intensity ('1045P', 'R110', '101-14' and '161-49C') mainly due to a stronger contribution of the blue component (OD 620) suggesting a juvenility character of these wines (Ribéreau-Gayon et al., 2006a).

Color intensity was loaded into the PCA plot in the right quadrant while anthocyanin content was loaded on the left side. This behavior was expected since during bottle aging color intensity increases while anthocyanin decreases due to combination or breakdown reactions (Ribéreau-Gayon et al., 2006b). PPI followed the same trend of color intensity. The PPI test is performed to measure the concentration of procyanidins in 
wine. These molecules may react with anthocyanins to form reddish-orange complexes during aging in bottle (Ribéreau-Gayon et al., 2006a). The highest color intensity and PPI were observed in the lowest vigorous rootstock '161-49C'. The mechanism involved in these reactions and the influence of rootstock-scion interaction on phenolic compounds are still to be elucidated.

When rootstocks were grouped according to vigor, vine production and phenolic composition of the wine (Figure 5) had no clear separation of vigorous or less productive ones. Vigorous rootstocks, 'IAC 766' and 'Rup', induced an adequate balance between vegetative and reproductive growth of 'Syrah' grapevine under double pruning management, mainly in 2012, and consequently overall wine quality from these rootstocks did not vary from moderate or less productive rootstocks. Higher yielding rootstocks do not always have a negative impact on wine quality as long as vegetative and reproductive growth of the vine is balanced (Dry and Coombe, 2005).

\section{Conclusion}

The yield, grape and wine quality of Syrah grapevines grown under autumn-winter season through double pruning management could be improved by the use of high vigor rootstocks. The rootstocks 'IAC766', 'Rup' and 'Kober' increase grape production of 4-year-old 'Syrah' grapevines, without impairment on grape quality. The two highest yielding and vigorous rootstocks, 'Rup' and 'IAC766', also induce sufficient phenolic composition and alcohol acidity balance in 'Syrah' winter wine. In contrast, low vigor rootstock '161-49' do not show better wine composition and should not be recommended to Syrah grapevine conducted under double pruning management.

\section{Acknowledgments}

This study was financially supported by CAPES (Coordination for the Improvement of Higher Level Personnel), CNPq (Brazilian National Council for Scientific and Technological Development) and FAPEMIG (Minas Gerais State Foundation for Research Support). We thank Isa Magalhães Lima and Achson Lima for grape analysis and wine assistance, Daniel Rodrigues for helping in field evaluations, José Procópio Stella for the experimental vineyard and Cecílio Frois Caldeira Junior for PCA analysis.

\section{References}

Amerine, M.A.; Ough, C.S. 1980. Methods for Analysis of Musts and Wines. John Wiley, New York, NY, USA.

Bassoi, L.H.; Dantas, B.F.; Lima Filho, J.M.P.; Lima, M.A.C.; Leão, P.C.S.; Silva, D.J.; Maia, J.L.T.; Souza, C.R.; Silva, J.A.M.; Ramos, M.M. 2007. Preliminary results of a long-term experiment about RDI and PRD irrigation strategies in winegrapes in São Francisco Valley, Brazil. Acta Horticulturae 754: 275-282.
Cortell, J.M.; Halbleib, M.; Gallagher, A.V.; Righetti, T.L.; Kennedy, J.A. 2005. Influence of vine vigor on grape (Vitis vinifera L. cv. Pinot Noir) and wine proanthocyanidins. Journal of Agricultural and Food Chemistry 53: 5798-5808.

Dias, F.A.N.; Mota, R.V.; Favero, A.C.; Purgatto, E.; Shiga, T.M.; Souza, C.R.; Pimentel, R.M.A.; Regina, M.A. 2012. 'Syrah' vine on different rootstocks in winter cycle in the south of Minas Gerais State, Brazil. Pesquisa Agropecuária Brasileira 47: 208215 (in Portuguese, with abstract in English).

Dry, P.R.; Coombe, B.G. 2005. Viticulture. 1. Resources. Winetitles, Adelaide, Australia.

Favero, A.C.; Amorim, D.A.; Mota, R.V.; Soares, A.M.; Souza C.R.; Regina, M.A. 2011. Double-pruning of 'Syrah' grapevines: a management strategy to harvest wine grapes during the winter in the Brazilian Southeast. Vitis 50: 151-158.

Giusti, M.M.; Wrosltad, R.E. 2000. Characterization and Measurement of Anthocyanins by UV-Visible Spectroscopy: Current Protocols in Food Analytical Chemistry. John Willey, New York, NY, USA.

Jackson, D.I.; Lombard, P.B. 1993. Environmental and management practices affecting grape composition and wine quality: a review. American Journal of Enology and Viticulture 44: 409-430.

Kidman, C.M.; Dry, P.R.; McCarthy, M.G.; Collins, C. 2013. Reproductive performance of Cabernet Sauvignon and Merlot (Vitis vinifera L.) is affected when grafted to rootstocks. Australian Journal of Grape and Wine Research 19: 409-421.

Kliewer, W.M.; Dokoozlian, N.K. 2005. Leaf area/crop weight ratios of grapevines: influence on fruit composition and wine quality. American Journal of Enology and Viticulture 56: 170-181.

Kodur, S.; Tisdall, J.M.; Clingeleffer, P.R.; Walker, R.R. 2013. Regulation of berry quality parameters in 'Shiraz' grapevines through rootstocks (Vitis). Vitis 52: 125-128.

Main, G.; Morris, J.; Striegler, K. 2002. Rootstock effects on Chardonel productivity, fruit, and wine composition. American Journal of Enology and Viticulture 53: 37-40.

Mazza, G.; Miniati, E. 1993. Anthocyanines in Fruits, Vegetables, and Grains. CRC Press, Boca Raton, FL, USA.

Mota, R.V.; Silva, C.P.C.; Favero, A.C.; Purgatto, E.; Shiga, T.M.; Regina, M.A. 2010. Physico-chemical composition of wine grapes berries in summer and winter growing seasons. Revista Brasileira de Fruticultura 32: 1127-1137 (in Portuguese, with abstract in English).

Ortega-Regules, A.; Romero-Cascales, I.; Ros-García, J.M.; BautistaOrtín, A.B.; López-Roca, J.M.; Fernández-Fernández, J.I.; GómezPlaza, E. 2008. Anthocyanins and tannins in four grape varieties (Vitis vinifera L.): evolution of their content and extractability. International Journal of Vine and Wine Sciences 42: 147-156.

Pereira, G.E.; Gaudillere, J.P.; Pieri, P.; Hilbert, G.; Maucourt, M.; Deborde, C.; Moing, A.; Rolin, D. 2006. Microclimate influence on mineral and metabolic profiles of grape berries. Journal of Agricultural and Food Chemistry 54: 6765-6775.

Regina, M.A.; Mota, R.V.; Souza, C.R.; Favero, A.C. 2011. Viticulture for fine wines in Brazilian southeast. Acta Horticulturae 910: 113-120.

Regina, M.A.; Pereira, G.E.; Cançado, G.M.A.; Rodrigues, D.J. 2000. Calculation of grapevine leaf area by non-destructive method. Revista Brasileira de Fruticultura 22: 310-313 (in Portuguese, with abstract in English). 
Renouf, V.; Tregoat, O.; Roby, J.P.; Van Leeuwen, C. 2010. Soils, rootstocks and grapevine varieties in prestigious Bordeaux vineyards and their impact on yield and quality. Journal International des Sciences de la Vigne et du Vin 44: $127-134$.

Ribéreau-Gayon, P.; Glories, Y.; Maujean, A.; Dubourdieu, D. 2006a. Phenolic Compounds. p. 141-204. In: Ribéreau-Gayon, P.; Glories, Y.; Maujean, A.; Dubourdieu, D., eds. Handbook of enology. vol. 2. The chemistry of wine: stabilization and treatments. John Wiley, New York, NY, USA.

Ribéreau-Gayon, P.; Glories, Y.; Maujean, A.; Dubourdieu, D. 2006b. Aging red wines in vat and barrel: phenomena occuring during aging. p. 387-428. In: Ribéreau-Gayon, P.; Glories, Y.; Maujean, A.; Dubourdieu, D., eds. Handbook of Enology, vol. 2. The chemistry of wine: stabilization and treatments. John Wiley, New York, NY, USA.

Rühl, E.H. 2000. Effect of rootstock and $\mathrm{K}^{+}$supply on $\mathrm{pH}$ and acidity of grape juice. Acta Horticulturae 512: 31-37.

Satisha, J.; Somkuwar, K.G.; Sharma, J.; Upadhyay, A.K.; Adsule, P.G. 2010. Influence of rootstocks on growth yield and fruit composition of Thompson seedless grapes grown in the Pune region of India. South African Journal of Enology and Viticulture 31: 1-8.
Smart, D.R.; Schwass, E.; Lakso, A.; Morano, L. 2006. Grapevine rooting patterns: a comprehensive analysis and a review. American Journal of Enology and Viticulture 57: 89-98.

Smart, R.; Robinson, M. 1991. Sunlight into the wine: a handbook for winegrape canopy management. Winetitles, Adelaide, Australia.

Spayd, S.E.; Tarara, J.M.; Mee, D.L.; Ferguson, J.C. 2002. Separation of sunlight and temperature effects on the composition of Vitis vinifera cv. Merlot Berries. American Journal of Enology and Viticulture 53: 171-182.

Soar, C.J.; Dry, P.R.; Loveys, B.R. 2006. Scion photosynthesis and gas-exchange in Vitis vinifera L. cv. Shiraz: mediation of rootstock effects via xylem sap ABA. Australian Journal of Agricultural Research 12: 82-96.

Souza, C.R.; Mota, R.V.; França, D.V.C.; Pimentel, R.M.A.; Regina, M.A. 2015. Performance of Cabernet Sauvignon grafted onto different rootstocks during the autumn-winter season in Brazilian southeast. Scientia Agricola 72: 138-146.

Vasconcelos, M.C.; Greven, M.; Winefield, C.S.; Trought, M.C.T.; Raw, V. 2009. The flowering process of Vitis vinifera: a review. American Journal of Enology and Viticulture 60: 411-434.

Walker, R.; Clingeleffer, P. 2009. Rootstock attributes and selection for Australian conditions. Australian Viticulture 13: 70-76. 